\title{
Research on Knowledge-Oriented Supply Chain Risk Management System Model
}

\author{
Yingchun Guo \\ College of Mathematics and Computer Science, Hebei University, Baoding 071002, China \\ E-mail: guoyc@hbu.edu.cn
}

Received: May 10, 2011 Accepted: June 5, $2011 \quad$ doi:10.5430/jms.v2n2p72

\begin{abstract}
Based on analyzing the characteristics of supply chain risk management under the influences of knowledge, in this paper integrates basic theories and methods of knowledge management into the process of risk management, builds a knowledge-oriented supply chain risk management system model, and proposes relevant strategies, presenting references for practical application of knowledge-oriented supply chain risk management. By means of acquiring, storing, sharing, and transferring supply chain risk knowledge and knowledge innovation, it can ensure the knowledge supply for the whole process of supply chain operation management and risk management, effectively blocking the evolution and transmission of risks in supply chain, realizing the added value of activities in supply chain, and improving the performance of supply chain.
\end{abstract}

Keywords: Supply chain risk management, Knowledge-oriented, Dynamic knowledge alliance, System model

\section{Introduction}

The globalization of economy produces unprecedented opportunities for the development of enterprises on one hand. On the other hand, it increases the risks of business. Along with the progress of information technology and the intensified competition, supply chain management has become one of key elements for enterprises winning competition advantages. Supply chain has many participators, covers different areas, and includes various links, what make it vulnerable to influences of uncertain factors from external environment and all parties in the supply chain, forming the supply chain risk.

Supply chain risk management (SCRM) is a cross-field of supply chain management and risk management. It focuses on how to control the factors that may cause negative effects on the normal operation of supply chain and their impacts, and how to ensure the realization of supply chain management goals by improving the reliability of the supply chain. The implement of supply chain risk management in enterprises can not only defend supply chain risks effectively, but also reduce losses as much as possible after the occurrence of risks (Tang 2006).

The process of supply chain risk management will produce amounts of knowledge associated with supply chain risks, such as cause-effect relations, effects of risk events, and strategies of handling risk events. The knowledge is very important for supply chain risk management. Between supply chain enterprises there are transmission of values, sharing of knowledge, and exchange of risks. Without the knowledge, supply chain risk management is empty. To manage the knowledge well is bound to improve the effect of supply chain risk management.

Currently, few studies concern the application of supply chain risk management by knowledge management. Wu and Zhang (2007) emphasized that the sharing of knowledge is the core of knowledge management in supply chain management and propose some main strategies for the sharing of knowledge in supply chain. Zhao, Du and Qin, (2008) built a technological innovation value model for the sharing of knowledge in supply chain and considered that the sharing of knowledge in supply chain can help to achieve the maximum value of technological innovation. Cui, Chen and Zhang (2009) pointed out that customer knowledge management is an inevitable choice to improve the core competence of supply chain.

Ireland and Webb (2007) used a multi-theoretic perspective, discussing four strategies that firmed use to balance a climate of trust and power in a strategic supply chain. Seuring and Müller (2008) studied a literature review of a conceptual framework for sustainable supply chain management and outlined major lines of research in the field. Pereira (2009) developed a modeling approach as a tool to support the strategy that uses IT to make supply chain more robust and resilient. Trkman and McCormack (2009) discussed supply chain risk in turbulent environments - a conceptual model for managing supply chain network risk and presenting preliminary research concepts regarding a new approach 
to the identification and prediction of supply risk. Braunscheidel and Suresh (2009) discussed the organizational antecedents of a firm's supply chain agility for risk mitigation and response. Wang, Stößlein and Wang (2010) proposed an advanced method that takes into consideration typical problems in group decision-making processes by applying linguistic operators derived from the field of decision theory and fuzzy-sets theory and offered advice on the mitigation of risks in Knowledge Supply Networks (KSN). Tuncel and Alpan (2010) showed that the system performance could be improved by using risk management actions and the overall system costs could be reduced by mitigation scenarios. Giannakis and Louis (2011) developed a framework for the design of a multi-agent based decision support system for the management disruptions and mitigation of risks in manufacturing supply chains.

These articles present some research lines for how to apply knowledge management to supply chain management. But they seldom study how to apply the theories and methods of knowledge management to the implementation of supply chain management. Supply chain risk management and knowledge management respectively belong to separated and independent study field. In this paper, we analyze the characteristics of supply chain risk management under the influences of knowledge, build a knowledge-oriented supply chain risk management system model, and propose relevant strategies, presenting references for practical application of knowledge- oriented supply chain risk management.

\section{Characteristics of knowledge-oriented supply chain risk management}

To improve the level of supply chain risk management, we should not only rely on information exchange, but also upgrade information as the element of knowledge, making the effective use of information and its communication to control the occurrence of risks and the consequences. By referencing relevant studies, this paper is to analyze the characteristics of supply chain risk management from the perspective of the role of knowledge.

\subsection{Take the management of supply chain risk as the center, the improvement of supply chain performance as the goal}

The knowledge-oriented SCRM can promote the knowledge transfer and sharing in supply chain, integrating core enterprises, suppliers, and customers into one body. By acquiring, sharing, and using the explicit risk knowledge and the tacit knowledge inside and outside the enterprise, use the collective wisdom of enterprises at the supply chain node, coordinate and optimize the knowledge level of enterprise members in the supply chain, producing synergetic values, enhancing the integral ability of defending risks, and improving the whole performance of supply chain.

\subsection{Take the knowledge of supply chain risk as the base}

In supply chain risk management, it is insufficient for the enterprise at one node only knowing about its own risk. Only by taking all nodes as one unity, can it create the knowledge of whole supply chain process. Make proper risk analysis and accumulate risk knowledge during the operation of supply chain, provide knowledge for supply chain by a knowledge-sharing platform, offer knowledge services for the reengineering of supply chain management organization, procedure, and operation mode by applying the knowledge management system, in order to improve the overall competitiveness of supply chain.

\subsection{Take information and network technology as the support}

Information and network technologies serve as technological guaranty for the application of knowledge-oriented supply chain risk management. The sharing and communication of knowledge among organization members in supply chain are the core contents of knowledge management and supply chain risk management. A perfect network platform can not only guarantee immediate information and knowledge exchange between enterprises at different nodes, improving the timeliness of knowledge communication, but also help to give risk warnings and handle risk emergencies.

\subsection{Take the dynamic knowledge alliance as the organizational form}

The sharing and communication of risk knowledge must across the organizational barriers between enterprise members in supply chain, what is the key for supplying and using the knowledge of whole supply chain risk management. Member enterprises are complementary in businesses and abilities. Only by achieving the sharing and communication of knowledge among member enterprises, can it effectively improve the anti-risk ability of supply chain. A dynamic knowledge alliance is an effective organizational form. The core enterprise takes the lead, and selects enterprises that possess necessary knowledge sources to form the alliance. The dynamic changes of enterprises members in supply chain will lead to the continuous update and reengineering of knowledge, realizing the dynamic optimization of supply chain.

\subsection{Continuous planning}

The knowledge-oriented SCRM is not temporary but a long-term task. The process of risk identification, assessment, decision-making, and monitoring, together with the circular ascendant of knowledge generation, transformation, application, and renewal, make the knowledge-oriented SCRM in a dynamic continuous state. Therefore, supply chain risk managers should make continuous plans and emphasize on periodical exchange of risk management experience and 
knowledge with suppliers, dealers, and other cooperative partners, together participate into the rings of product development, production, and sale service, and adopt the universal system to realize the timely sharing of information and knowledge, displaying the effectiveness of knowledge-oriented SCRM.

\section{The constitution of knowledge-oriented supply chain risk management system}

Based on analyzing the characteristics of knowledge-oriented SCRM, we consider that by reforming the acquirement, storage, sharing, and transformation of supply chain risk knowledge and knowledge innovation, we can improve the supply of risk knowledge during the entire supply chain risk management process (risk identification, risk assessment, risk decision-making, and risk monitoring), and build a perfect knowledge management system, integrating the business processes of enterprises at all nodes, controlling elements of risks effectively, reducing the probability of risks, alleviating consequences of risks, improving the knowledge level of managers and employees and their recognition to supply chain risks, driving the use of knowledge, and enhancing the overall level of supply chain risk management.

In order to make sure to conduct the whole process of knowledge acquirement, application, and innovation in knowledge- oriented SCRM orderly, in this paper the author builds a knowledge-oriented SCRM system model frame, composed of the level of knowledge sources, the level of knowledge generation, the level of knowledge storage, and the level of knowledge application (see Figure 1). This system takes supply chain risk management as the core. The key is to integrate the knowledge management systems of enterprises at different nodes, provide a unified open network platform achieving immediate knowledge exchange, and reduce time and space restrictions of knowledge sharing. Enterprises at different nodes respond simultaneously according to the real demand information and knowledge.

\subsection{Level of knowledge sources}

Collect the individual information and overall information of supply chain, such as history data, experts' suggestions, planned results, and environmental information as the sources of generating risk knowledge, including internal knowledge sources and external environmental knowledge sources.

\subsection{Level of knowledge generation}

By data mining and knowledge discovery, acquire and abstract risk knowledge, such as knowledge of risk identification, and knowledge of risk assessment. Display them in certain forms, such as cause-effect figure, risk verification table, and risk assessment measuring.

\subsection{Level of knowledge storage}

Set up technological standards for knowledge presentation, storage, and communication, and use the information platform that covers all enterprises in supply chain, connecting all member enterprises' knowledge sources together by network. Store the collected risk knowledge in a dynamic knowledge database, and build a platform for exchanging knowledge between member enterprises in supply chain by knowledge map, expert system, and other technologies.

\subsection{Level of knowledge application}

Form a dynamic knowledge alliance, and make the communication and coordination between managers and employees of member enterprises achieve knowledge sharing, application, and innovation, offering basis for risk treatment and risk decision. Knowledge portal and knowledge-sharing platform supply a interface for knowledge operation. Members of knowledge alliance can find and use specific information and knowledge based on needs.

\section{The implement of knowledge-oriented supply chain risk management}

\subsection{Emphasize on the accumulation of supply chain risk knowledge}

Supply chain risk management-related knowledge can be divided into internal knowledge and external knowledge according to the sources. External knowledge includes systematic theories of supply chain operation management and risk management, knowledge of supply chain operation environment, other enterprises' experiences of risk management and best practices, etc. Internal knowledge includes risk management experiences, rules and system, technological standards and product regulations, cooperation contracts, etc.

Supply chain risk management is a process of combining theoretical knowledge, practical experiences, tools, and methods together. The application of knowledge-oriented SCRM should emphasize on the knowledge of daily logistics, systematically mining, storing, and transforming the explicit knowledge and tacit knowledge accumulated in the process of risk management practice. Meanwhile, it is necessary to absorb ordinary external knowledge and learn best practices from others, providing managers with explicit knowledge in the form of information materials and assisting tools, and providing them with tacit knowledge in the form of cases. 
Member enterprises in supply chain should store their internal and external knowledge into the dynamic knowledge database, and offer intelligent fast retrieving services for others knowing sorts of knowledge. A powerful knowledge supply guarantees more effective risk identification, assessment, decision, and monitoring.

\subsection{Build a dynamic knowledge alliance and achieve knowledge sharing}

4.2.1 Form a trans-organizational risk management agency, build a dynamic knowledge alliance, and achieve the trans-organizational flow and sharing of knowledge

The key for the application of knowledge-oriented SCRM is to across the organizational obstacles, achieving the close cooperation of enterprises at all nodes of supply chain. The core enterprise in the supply chain takes the lead and forms a trans-organizational supply chain risk management agency to coordinate the risk management activities. Build a dynamic knowledge alliance, constitute the risk management planning, and supervise the application of supply chain risk management, such as establishing a good knowledge-sharing incentive mechanism and mutual trust mechanism. Select alliance partners that possess strong learning abilities. The knowledge levels of member enterprises in supply chain are complementary and coordinative. Build an organizational culture of mutual trust and mutual learning. By this way, it can satisfy member enterprises' requirements for knowledge. Improve the quality and functions of products and services by good knowledge collaboration, improving the overall performance of supply chain.

4.2.2 Standardize knowledge of supply chain risk, build an information platform, and develop knowledge portals to improve the efficiency of knowledge communication

Establish technological standards for knowledge representation, storage, and communication. Build a knowledge exchange platform covering enterprises in supply chain based on information platforms in these enterprises, connecting the knowledge sources of member enterprises by the net. Use knowledge map, expert system, and knowledge engineering to develop a dynamic knowledge system for supply chain management. Open a network connection for external knowledge, extend the knowledge sources, and help all member enterprises to acquire new knowledge dynamically and effectively, achieving the acquirement, transfer, application, and innovation of risk management knowledge, and guaranteeing the knowledge supply at all links of supply chain risk management.

\subsection{The coordinative innovation based on supply chain risk knowledge}

The coordinative innovation based on supply chain risk knowledge is an important content of knowledge-oriented SCRM. Knowledge is a new thought derived from complex information, providing knowledge services for the reengineering of supply chain management organization, procedures, and operation modes, in order to improve the overall competitiveness of supply chain. Knowledge portals, running by one account, provide a unified entrance for enterprises at all nodes accessing useful knowledge, and facilitate the knowledge coordination between member enterprises. Evaluate and amend the knowledge during the interaction of knowledge according to changes of market environment, and achieve the knowledge innovation that meets the goal of supply chain management. The coordinative innovation based on supply chain risk knowledge is displayed in Figure 2.

To optimize the distribution of logistics resources and reduce the operation risk of supply chain is an important aspect of coordinative innovation. In order to deliver commodities timely, safely, exactly, and economically, we should make reasonable planning and technological reform for enterprises in supply chain. By means of knowledge network, enterprises in supply chain can locate separately according to the supply and demand in market. Logistics equipments and resources that belong to different systems can be connected thought virtual enterprises. By scientific planning and reengineering, make best use of advantages of logistics equipments and services, expand the radius of service and the space for goods distribution, optimize the supply chain, and improving the service level.

\section{Conclusion}

In the process of supply chain operation and risk management, the untimely, insufficient, and improper supply and sharing of specific knowledge is the essential reason for restricting the improvement of supply chain risk management level. In this paper, we studied how to integrate basic theories of knowledge management and methods into the process of risk management, and builds a knowledge-oriented supply chain risk management system model. Supply chain risk knowledge's acquirement, storage, sharing, and transformation, and knowledge innovation can supply knowledge for the whole process of supply chain operation management and risk management, reducing the possibility of risks and consequences in supply chain, realizing the added value of activities in supply chain, and improving the performance of supply chain. The research on knowledge innovation mechanism in supply chain risk management will be the direction of further studies. 


\section{References}

Cui, Ming., Chen, Jiping \& Zhang, Xiaoyan. (2009). Study on customer knowledge management oriented towards agile supply chain. Journal of Anhui University (Philosophy and Social Sciences), 33(1), 140-144.

Gonca Tuncel \& Gülgün Alpan. (2010).Risk assessment and management for supply chain networks: A case study. Computers in Industry, 61(3), 250-259, doi:10.1016/j.compind.2009.09.008. http://dx.doi.org/10.1016/j.compind.2009.09.008

Jorge Verissimo Pereira.(2009). The new supply chain's frontier: Information management. International Journal of Information Management, 29(5), 372-379,doi:10.1016/j.ijinfomgt.2009.02.001. http://dx.doi.org/10.1016/j.ijinfomgt.2009.02.001

Michael J. Braunscheidel, Nallan \& C. Suresh. (2009). The organizational antecedents of a firm's supply chain agility for risk mitigation and response. Journal of Operations Management, 27(2), 119-140, doi:10.1016/j.jom.2008.09.006 . http://dx.doi.org/10.1016/j.jom.2008.09.006

Mihalis Giannakis \& Michalis Louis. (2011). A multi-agent based framework for supply chain risk management Journal of Purchasing and Supply Management, 17(1), 23-31, doi:10.1016/j.pursup.2010.05.001. http://dx.doi.org/10.1016/j.pursup.2010.05.001

Peter Trkman, \& Kevin McCormack.(2009). Supply chain risk in turbulent environments--A conceptual model for managing supply chain network risk. International Journal of Production Economics, 119(2), 247-258, doi:10.1016/j.ijpe.2009.03.002. http://dx.doi.org/10.1016/j.ijpe.2009.03.002

R. Duane Ireland \& Justin W. Webb. (2007). A multi-theoretic perspective on trust and power in strategic supply chains. Journal of Operations Management, 25(2), 482-497,doi:10.1016/j.jom.2006.05.004. http://dx.doi.org/10.1016/j.jom.2006.05.004

Stefan Seuring \& Martin Müller. (2008). From a literature review to a conceptual framework for sustainable supply chain management. Journal of Cleaner Production, 16(15), 1699-1710, doi:10.1016/j.jclepro.2008.04.020. http://dx.doi.org/10.1016/j.jclepro.2008.04.020

Tang C. S. (2006).Perspectives in supply chain risk management. International Journal of Production Economics, 103(2), 451-488. doi:10.1016/j.ijpe.2005.12.006. http://dx.doi.org/10.1016/j.ijpe.2005.12.006

Wang Xiwei, Martin Stößlein \& Wang Kan. (2010) Designing knowledge chain networks in China - A proposal for a risk management system using linguistic decision making.Technological Forecasting and Social Change, 77(6), 902-915, doi:10.1016/j.techfore.2010.01.002. http://dx.doi.org/10.1016/j.techfore.2010.01.002

Wu, Chengfeng \& Zhang, Qingpu. (2007). Research on knowledge sharing in agile supply chain. Journal of Information, 6, 35-37.

Zhao, Huixia., Du, Rong \& Qin, Chuandong. (2008). Research on the value of technological innovation based on trans-unit knowledge sharing in agile supply chain. Chinese Journal of Management Science, S1, 426-429. 


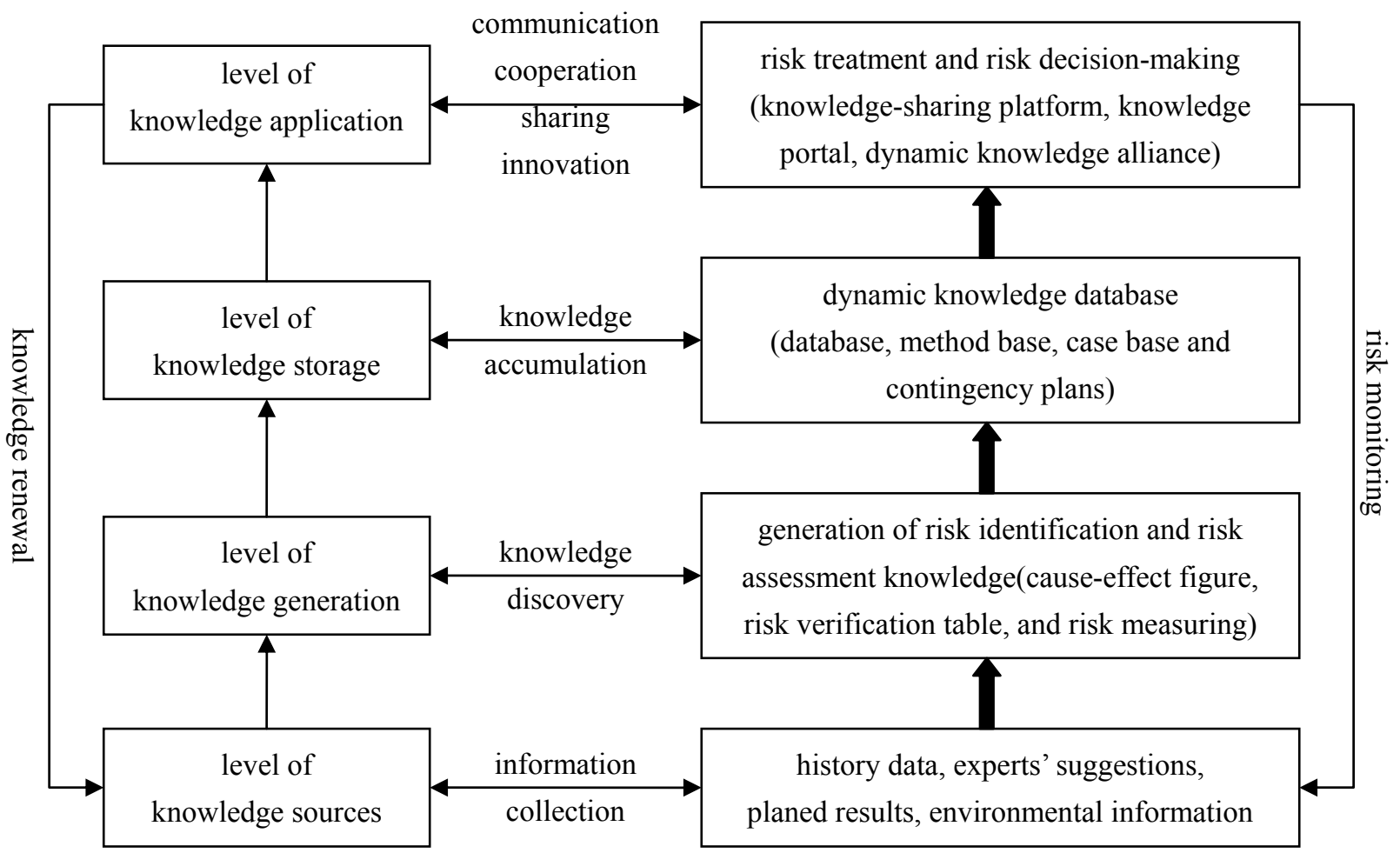

Figure 1. The Knowledge-Oriented SCRM System Model Frame

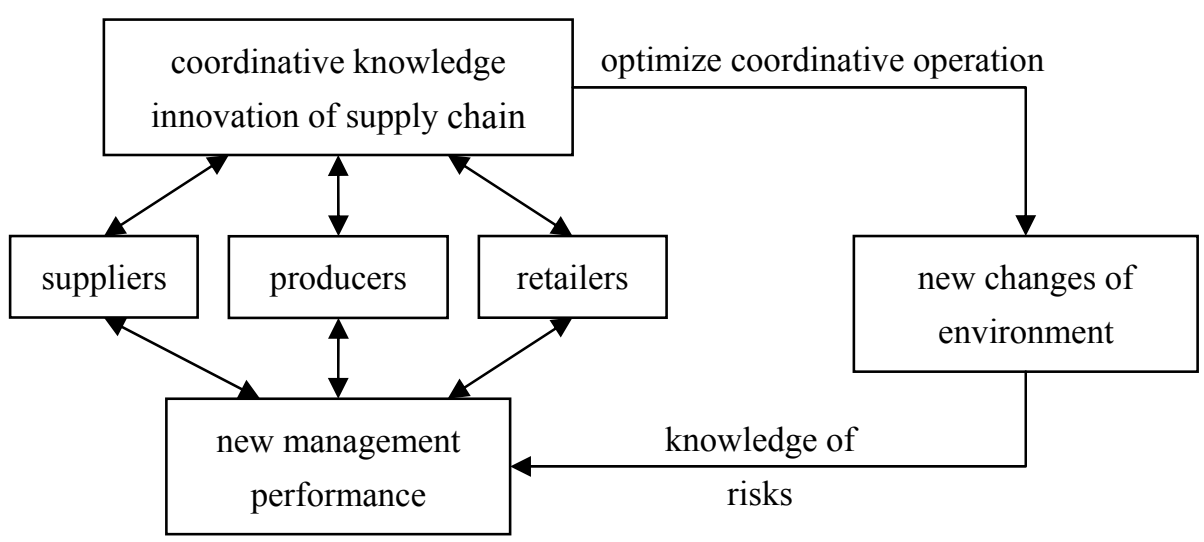

Figure 2. The Coordinative Innovation based on Supply Chain Risk Knowledge 